\title{
Decompositional Representation of Morphological Complexity: Multivariate fMRI Evidence from Italian
}

\author{
Francesca Carota $^{1,2}$, Mirjana Bozic ${ }^{1,2}$, and William Marslen-Wilson ${ }^{1,2}$
}

\begin{abstract}
Derivational morphology is a cross-linguistically dominant mechanism for word formation, combining existing words with derivational affixes to create new word forms. However, the neurocognitive mechanisms underlying the representation and processing of such forms remain unclear. Recent crosslinguistic neuroimaging research suggests that derived words are stored and accessed as whole forms, without engaging the left-hemisphere perisylvian network associated with combinatorial processing of syntactically and inflectionally complex forms. Using fMRI with a "simple listening" no-task procedure, we reexamine these suggestions in the context of the rootbased combinatorially rich Italian lexicon to clarify the role of semantic transparency (between the derived form and its stem) and affix productivity in determining whether derived forms are decompositionally represented and which neural systems are involved. Combined univariate and multivariate analyses reveal
\end{abstract}

\section{INTRODUCTION}

Derivational morphology is a cross-linguistically dominant strategy for creating new words (or lexemes) through the combination of existing words and morphemes with a derivational affix (e.g., happy + -ness $\rightarrow$ happiness). However, the neurocognitive mechanisms underlying the representation and processing of such derived forms are still unclear. Psycholinguistic theories of morphological processing propose diverging hypotheses on how such forms are represented in the mental lexicon, ranging from strong full-listing models (e.g., Butterworth, 1983) to fully decompositional accounts (e.g., Taft, 2004). These are difficult to reconcile within a coherent interpretive framework as well as with the very diverse neuropsychological and neuroimaging literature on derivational processing in different languages (e.g., Leminen et al., 2011; Meinzer, Lahiri, Flaisch, Hannemann, \& Eulitz, 2009; Marangolo et al., 2003; Badecker \& Caramazza, 1991). This has motivated a systematic cross-linguistic exploration of the processing of derivational morphology in its neurobiological context (for a review, see Marslen-Wilson, Bozic, \& Tyler,

\footnotetext{
${ }^{1}$ University of Cambridge, ${ }^{2}$ MRC Cognition and Brain Sciences Unit, Cambridge, United Kingdom
}

a key role for semantic transparency, modulated by affix productivity. Opaque forms show strong cohort competition effects, especially for words with nonproductive suffixes (ventura, "destiny"). The bilateral frontotemporal activity associated with these effects indicates that opaque derived words are processed as whole forms in the bihemispheric language system. Semantically transparent words with productive affixes (libreria, "bookshop") showed no effects of lexical competition, suggesting morphologically structured co-representation of these derived forms and their stems, whereas transparent forms with nonproductive affixes ( pineta, pine forest) show intermediate effects. Further multivariate analyses of the transparent derived forms revealed affix productivity effects selectively involving left inferior frontal regions, suggesting that the combinatorial and decompositional processes triggered by such forms can vary significantly across languages.

2014), aimed at uncovering the neurocognitive properties of derivationally complex forms.

\section{Bihemispheric Framework for Spoken Language Comprehension}

This research assumes that spoken language comprehension relies on interdependent but functionally dissociable neurobiological substrates: a bihemispheric system, underlying general perceptual and semantic/pragmatic interpretation of auditory input, and a left-hemisphere (LH) frontotemporal system, linking left inferior frontal gyrus (LIFG) with posterior temporal regions, that is selectively involved in the decompositional analysis of morphosyntactically complex sequences, including inflected words (Marslen-Wilson et al., 2014; Bozic, Tyler, Ives, Randall, \& Marslen-Wilson, 2010; Marslen-Wilson \& Tyler, 2007). A series of cross-linguistic fMRI studies in English, Polish, and Russian focused on the patterns of neural activation associated with derivationally complex forms, with the consistent finding that derived words like English bravely or Polish czytanie, "reading" (from czytać, "to read") robustly engaged the bilaterally distributed frontotemporal system previously shown to support the perceptual interpretation of simple monomorphemic words (Bozic et al., 2010) but 
did not selectively activate the left-lateralized frontotemporal system (Bozic, Szlachta, \& Marslen-Wilson, 2013; Bozic, Tyler, Wingfield, Su, \& Marslen-Wilson, 2013). This selective LH activation seems to be a hallmark of decompositional and combinatorial linguistic processing. In a further, more direct contrast between complex derived forms in Russian and matched inflectionally and syntactically complex forms, the derived forms activated only bilateral temporal regions, whereas inflectional and syntactic complexity in addition strongly activated LIFG (Klimovich-Smith, Bozic, \& Marslen-Wilson, under review). These results, apparently challenging both strong and weak decompositional accounts of morphological processing (e.g., Taft, 2004; Marslen-Wilson, Tyler, Waksler, \& Older, 1994), suggested that, unlike inflections, derived words are stored as whole-word form representations and that they are not accessed decompositionally via their constituent stem and affix morphemes.

This, however, cannot be the full story, because activation within the bihemispheric system is modulated by the perceptual and linguistic complexity of derived words. Earlier research with morphemically simple forms with onset embedded competitor words (e.g., clamp with onset embedded clam) shows bilaterally distributed increases in activation as a function of the relative frequency of the whole form and the onset-embedded competitor (e.g., Szlachta, Bozic, Jelowicka, \& MarslenWilson, 2012; Bozic et al., 2010). The higher the relative frequency of the competitor, the stronger the increase in activation. This cohort competition effect (MarslenWilson, 1987), which is assumed to reflect competition between two (or more) simultaneously active word candidates, is also seen cross-linguistically for a variety of derived and pseudoderived forms. In English (Bozic, Tyler, et al., 2013), apparent competition effects are seen not only for semantically opaque stems with either productive or nonproductive suffixes (e.g., archer, breadth) but also for transparent stems combined with a nonproductive suffix (e.g., warmth). Similar bilateral temporal competition effects are also seen in Polish (Bozic, Szlachta, et al., 2013; Szlachta et al., 2012), both for derivationally simple words with an onset-embedded pseudostem (e.g., kotlet/kot, "cutlet"/cat") and for opaque suffixed forms (e.g., sekretarz/sekret, "secretary"/"secret"). These competition effects, sensitive to the relative frequencies of the whole form and of the onset embedded competitor, are consistent with the view that derived and pseudoderived words are accessed nondecompositionally as stored whole forms, in the same way as morphologically simple words.

It is striking, therefore, that no competition effects are seen, either in English or Polish, for transparent derived forms with productive affixes. In the English data (Bozic, Tyler, et al., 2013), transparent productive forms (e.g., bravely) patterned with simple monomorphemic words that have no onset-embedded competitor (e.g., giraffe), suggesting that the onset-embedded stems of these forms (e.g., brave), unlike the embedded stems of words like warmth and archer, were not functioning perceptually as cohort competitors with the whole form. The same outcome is seen for Polish (Bozic, Szlachta, et al., 2013), where a direct comparison between transparent forms (e.g., czytanie, "reading") and opaque forms (e.g., sekretarz, "secretary"), where the two stimulus sets were matched for level of competition between embedded stem and whole form, showed robust competition effects in bilateral temporal cortex for the opaque items, but no effects for the transparent items (all of which had productive affixes).

These results are inconsistent with a uniform wholeform account for derivational morphology in the languages tested. The finding that an onset-embedded stem like brave does not generate cohort competition with its whole form bravely seems to require some degree of morphological parsing and decompositional representation for transparent derived forms with productive affixes. This is consistent with earlier theoretical claims (e.g., Marslen-Wilson, 2007; Clahsen, Sonnenstuhl, \& Blevins, 2003; Meunier \& Segui, 2002) and with behavioral research (in both English and Polish) contrasting transparent and opaque derived forms in cross-modal priming paradigms. Studies in English (e.g., Marslen-Wilson et al., 1994) show significant priming between semantically transparent derived forms and their stems (bappiness/ bappy) but not for synchronically opaque pairs (e.g., witness/wit). Identical results are seen for Polish (Reid \& Marslen-Wilson, 2003), contrasting transparent pairs like szycie/szyć "sewing/to sew" with opaque pairs such as jatowiec/jatowy "a juniper/poor, futile."

These results, together with the direct neuroimaging evidence that onset-embedded transparent stems do not function as cohort competitors, point to underlying differences in the lexical representation of transparent as opposed to opaque forms, coupled with decompositional processing during lexical access. The absence of cohort competition is consistent, in fact, with the type of decompositional account proposed by Marslen-Wilson et al. (1994), where the same morphemic representation (e.g., happy) functions both as an independent lexeme and as a combinatorial component of associated transparent derived forms (e.g., happily, happiness, unhappy). These inferences, however, do not sit well with the repeated failure to see any selective activation of the $\mathrm{LH}$ frontotemporal system. This system, as noted above, is critically involved in the language-specific decompositional and combinatorial processes that support inflectional morphology and hierarchical syntax. There seems no a priori reason why such a system should not also support the application of these processing functions to derivationally complex forms with the appropriate synchronic properties of semantic transparency and affix productivity. Indeed, the Bozic, Tyler, et al. (2013) study was conducted on just this assumption, where forms like bravely and happiness were expected to behave, 
neurocognitively, in the same way as regular inflectional forms. The absence of selective LH activation, for both Polish and English transparent forms, suggests either that these forms are not in fact combinatorially processed or that such processes can also be supported by bihemispheric, potentially more domain-general systems, consistent with recent claims for aspects of syntactic processing (Bozic, Fonteneau, Su, Marslen-Wilson, 2015).

In the fMRI study reported here, we seek to move these issues forward by examining them (a) in a language (Italian) with a much richer and potentially more combinatorial derivational word formation system than English, where (b) well-developed computational lexicographic resources are available for determining the relevant distributional properties of the language along the dimensions of affix (and stem) productivity, ${ }^{1}$ and (c) by employing both univariate analysis techniques, primarily sensitive to average differences in overall neural activation between conditions, and multivariate pattern analysis techniques (Nili et al., 2014; Kriegeskorte, Mur, \& Bandettini, 2008) that are potentially more sensitive to the qualitative properties of neural computations elicited by different linguistic inputs. In this context, and using the presence or absence of cohort competition effects as an index of underlying decompositional representation, we aim to clarify under what conditions and in which brain regions derivationally complex forms are represented either morphemically or as unanalyzed whole forms.

\section{Transparency, Productivity, and Competition in Italian Derivational Morphology}

Italian is a Romance language with a root-based morphology in which derivational and inflectional suffixes specify different types of morphosemantic and morphosyntactic information. A semantically transparent derived word like libreria, "bookshop," for example, can be decomposed into the stem morpheme $\operatorname{libr}(O)$, "book," the productive derivational suffix -eri- (with a locative meaning usually linked to a commercial activity), plus the inflectional ending $-a$, which marks both the feminine gender and the singular number (Carota, 2006). These processes are ubiquitous in Italian. About 30\% of the basic Italian vocabulary and more than $50 \%$ of the lexical entries coined in the 20th century (Iacobini, 2010) are derived by word formation processes involving more than 180 derivational suffixes (Grossmann \& Rainer, 2004), generating nouns, adjectives, verbs, and adverbs.

These derived constructions are part of a diachronically stratified lexicon and can often be traced back to the Latin origins of modern Italian, showing how a word formation mechanism evolved and became active or lost, producing semantically transparent and opaque words combined with productive and nonproductive affixes. For instance, in the opaque form ventura, "destiny," the nonproductive suffix -ura is appended to the embedded stem vent-, which is etymologically related to the form and meaning of "vent-urus," the future participle of the Latin verb venio, -ire, "to come," which no longer exists in Italian. Synchronically the apparent embedded stem form is vento, "wind," which is not semantically related to the meaning of the word. These properties of Italian derivational morphology make it possible for derived words in Italian to be systematically contrasted in terms of both their semantic transparency and their affix productivity, giving rise to a gradient of derivational complexity (cf., Bozic, Tyler, et al., 2013). We constructed highly controlled sets of stimulus words across four principal experimental conditions, overlapping with previous studies in English and Polish, to provide a robust test, in a new cross-linguistic environment, of the determinants of decompositional or whole-form representation of derived words.

As in previous neuroimaging and behavioral studies, the primary dimension is the synchronic semantic relatednessas assessed by native speakers' rating judgments-of the relationship between the meaning of the onset-embedded derivational base morpheme and the meaning of the derived full form, ranging from highly transparent forms like bravely or happiness to opaque forms like archer or breadth. The English and Polish fMRI studies consistently show increased activation and significant cohort competition effects for semantically opaque words, indicating that these forms and their onset-embedded stems or pseudostems are separately represented lexemes. The competition effects elicited by these forms activate bilateral brain regions, primarily in the middle temporal lobes. For semantically transparent forms, however, there is some indication that the presence or absence of cohort competition is modulated by the productivity of the derivational affixes involved, where productivity is a measure of whether a derivational suffix is currently in use to create new words in the language.

As noted above, Bozic, Tyler, et al. (2013) found that highly transparent derived forms with unproductive affixes, such as warmth (with the unproductive affix -th), nonetheless seemed to pattern with the semantically opaque forms (such as archer), showing comparable increases in levels of neural activation relative to baseline. Consistent with earlier behavioral research (e.g., Ford, Davis, \& Marslen-Wilson, 2010; Marslen-Wilson et al., 1994), this suggests that complex words with unproductive suffixes, even if semantically transparent, are less likely to be stored and processed decompositionally. On the other hand, in the multivariate analyses conducted in the same Bozic, Tyler, et al. (2013) study, no effects of productivity per se were seen, either as a main effect or in interaction with semantic relatedness and lexical competition. It is in any case unclear how generalizable these productivity effects might be cross-linguistically. The parallel Polish study (Bozic, Szlachta, et al., 2013), for example, did not contrast stimuli along this dimension, and only productive suffixes were used.

In the current study, therefore, transparency and productivity are fully crossed, giving a two-way set of contrasts similar to those tested in the original English study (Bozic, 
Tyler, et al., 2013). A first group of words consisted of semantically transparent forms with an intact synchronic link with the meaning of their derivational bases (as reflected in native speaker relatedness ratings) and using derivational suffixes productively employed in current Italian-as in the example libr-eria given above, with the embedded stem libro. The second group consisted of similarly rated semantically transparent words such as pin-eta, "pine forest," with the embedded stem pino, "pine tree," but combined with the nonproductive suffix "-eta." These are comparable to the warmth set in English (Bozic, Tyler, et al., 2013). Two corresponding sets of semantically opaque words were also formed with either productive or unproductive suffixes. Thus, the form tomb-ino, "manhole," with the semantically unrelated embedded stem tomba, "tomb," is combined with the productive diminutive suffix "-ino" to form the third group of stimuli, whereas the fourth group consisted of equally opaque forms like prem-ura, "urgency," with the opaque embedded stem prem-(ere), "to push" combined with the unproductive affix "-ura." These derivationally complex items were contrasted with a baseline condition containing simple words with no derivational internal structure (e.g., albero, "tree") and no onset-embedded stem.

For each of the four complex word sets, potential lexical competition is held constant, measured in terms of the frequency divergence between the embedded stem or pseudostem and the whole form. The higher the frequency of the stem relative to the whole form, the stronger should be the competition effect. In the Polish data (Bozic, Szlachta, et al., 2013), we saw a striking disjunction between transparent and opaque sets, with no lexical competition effects for the transparent items. We ask here whether this distinction also holds for Italian, with a similar root-based morphology to Polish, and whether these effects are modulated by affix productivity, with some indication from English (Bozic, Tyler, et al., 2013) that transparent forms with unproductive affixes are not decompositionally represented, so that competition effects should still be present. Finally, by using potentially more sensitive multivariate pattern analysis methods (Nili et al., 2014; Kriegeskorte et al., 2008), we will revisit the issue of whether selective left frontotemporal involvement can be detected for the maximally decomposable transparent productive conditions.

\section{METHODS}

\section{Participants}

Twenty healthy volunteers participated in the study. All participants were right-handed Italian native speakers with no history of developmental, neurological, or psychiatric disorders. They had normal or corrected-to-normal vision. All participants gave their informed consent to take part in the study and were remunerated for their time. Ethical approval was obtained from the Cambridge psychology research ethics committee.

\section{Materials and Design}

\section{Stimuli}

The experiment included five conditions with 80 words each (see Table 1). The analytical dimensions affecting morphological analysis and decomposability were covaried in Conditions 1-4, which included (1) semantically transparent words with productive suffixes (libr-eria, "bookshop"), (2) semantically transparent words with unproductive suffixes (pin-eta, "pine forest"), (3) semantically opaque words with productive suffixes (tomb-ino, "manhole"), and (4) semantically opaque words with unproductive suffixes (prem-ura, "urgency"). Condition 5 consisted of morphologically simple words (e.g., albero, "tree") with no derivational structure.

All words were extracted from the WaCky Wide Web Corpus (Baroni, Bernardini, Ferraresi, \& Zanchetta, 2009), consisting of more than 1.5 billion word tokens and 3.6 million word types, providing a wide synchronic sample of current Italian. The test words were selected from an initial list of 800 morphologically complex words by applying a series of selection criteria. These included behavioral evaluation, corpus-based quantitative assessment, and qualitative

Table 1. Experimental Design and Stimulus Properties

\begin{tabular}{|c|c|c|c|c|c|c|c|}
\hline & & \multicolumn{3}{|c|}{ Stem Properties } & \multicolumn{3}{|c|}{ Suffix Properties } \\
\hline \multicolumn{2}{|c|}{ Condition } & $\begin{array}{c}\text { Embedded } \\
\text { Stem }\end{array}$ & $\begin{array}{c}\text { Semantic } \\
\text { Relatedness }\end{array}$ & $\begin{array}{l}\text { Freq } \\
\text { Ratio }\end{array}$ & Suffix & Productive & $\begin{array}{c}\text { Corpus-based } \\
\text { Productivity }\end{array}$ \\
\hline 1 & Transparent productive (libr-eria) & Yes & 4.6 & 1.10 & Yes & Yes & 0.022 \\
\hline 2 & Transparent nonproductive (pin-eta) & Yes & 4.5 & 1.07 & Yes & No & 0.008 \\
\hline 3 & Opaque productive (tomb-ino) & Yes & 2 & 1.10 & Yes & Yes & 0.031 \\
\hline 4 & Opaque nonproductive (prem-ura) & Yes & 1.9 & 1.18 & Yes & No & 0.009 \\
\hline 5 & Simple (albero) & No & $\mathrm{n} / \mathrm{a}$ & $\mathrm{n} / \mathrm{a}$ & No & $\mathrm{n} / \mathrm{a}$ & $\mathrm{n} / \mathrm{a}$ \\
\hline
\end{tabular}

Relatedness $=$ average pretest scores of judged semantic relatedness $(0-5)$ between the whole word and the embedded stem; Freq ratio $=$ ratio of $\log$ stem frequency to log of lemma frequency of the derived word. 
grammatical/lexicographic validation with respect to three parameters: semantic transparency, suffix productivity, and lexical competition.

\section{Semantic Transparency}

An online rating study was conducted to assess the degree of semantic transparency of each experimental item, defined as the extent to which the meaning of the derived word was synchronically linked to the meaning of its embedded derivational base (e.g., cambiamento/ cambiare, "change/to change," vs. inventario/inventare, "inventory/to invent"). One hundred native Italian speakers took part in the study. They judged whether the meaning of each of the 800 complex words was related to the meaning of its embedded stem, using a 5-point scale. Complex words with ratings of $4-5$ for $75 \%$ of the participants were assigned to the transparent conditions. The opaque conditions were restricted to words with ratings of $1-3$ for $75 \%$ of the participants. The within-condition variation in rating scores was used to explore the specific effects of semantic relatedness for the different groups.

\section{Suffix Productivity}

This was defined as the probability $p$ that a suffix is used to create new words and measured as $p=b / N$, where $b$ is the number of hapax legomena (words with a given suffix that is attested only once in the corpus) and $N$ is the total number of tokens for that affix (Plag, 2006; Baayen \& Lieber, 1991). The average ratios for the four suffixed conditions are given in Table 1 . This corpus-based approach to suffix productivity assumes that if a complex word occurs only once in a corpus, then it is likely to be a new lexical entry resulting from a new combination of a stem and a suffix. As an additional check on whether a suffix was synchronically productive, we also determined whether it had been used to generate new words in the last 10 years. All the words classified as productive had suffixes that met this criterion.

\section{Lexical Competition}

This was defined as the ratio between the logarithmic frequencies of the onset-embedded stem or pseudostem and of the lemma of the derived form, as quantified by a corpus-based analysis. These measures were preferred to the simple stem form measure used in our earlier work on English (Bozic et al., 2010), because they better reflect the root-based morphological properties of the Italian lexicon, where inflectional grammatical morphemes mark the number and gender of nouns and adjectives and the person and tense/mood of the verbs. Thus, for a form like guidatore, "driver" with the stem guid- (from the verb guidare, "to drive"), the frequency of the verbal stem includes all of its inflectional and derivational suffixed variants (e.g., guidare, guidando, guida, guidava, guidatrice, guidatori), as attested in a large Italian corpus (Baroni et al., 2009), and the lemma of the derived form includes its inflectional forms (e.g., guidatore, guidatori). These competition ratios were held constant across the four derivational conditions.

These variables define a potential complexity gradient across the four primary experimental conditions, which covary morphosemantic transparency and productivity, while matching degree of lexical competition across these conditions (see Table 1). A fifth condition consisted of simple words with no derivational structure (e.g., albero "tree").

The conditions (in order 1-5) were matched on average number of phonemes (3.85, 3.82, 3.83, 3.85, 3.75), acoustic duration in seconds $(1.2,1.2,1.2,1.2,1.1), \log$ whole-word frequency $(3.52,3.47,3.56,3.60,3.38)$, and $\log$ lemma frequency $(3.86,3.65,3.85,3.88,3.74)$. Each condition contained words (almost all nouns) derived from either verbs (deverbal) or nouns (denominal).

The 400 test words were interspersed with 100 filler words, 200 acoustic baseline trials, and 200 null event trials (silence). The baseline was envelope-shaped, lengthmatched "Musical Rain" (MuR), sharing the auditory properties of the spoken words, without inducing phonetic interpretation. The baseline was created by extracting the temporal energy envelope from each spoken word and then filling these with jittered fragments of synthesized speech (Uppenkamp, Johnsrude, Norris, Marslen-Wilson, \& Patterson, 2006). The MuR stimuli so obtained are matched in root mean square levels and spectrotemporal energy distribution to the spoken stimuli but do not trigger a speech percept (Bozic et al., 2010).

\section{Experimental Procedure}

We adopted a "natural" listening task with an occasional 1-back memory task, intended to keep the participants awake and attentive. For 5\% of trials, a question appeared on the screen asking whether the meaning of the word they were hearing was the same as the previous one. Participants pressed a left button (same = YES) and a right button (different $=$ NO) with their left hand. There were a total of 900 trials, pseudorandomized across four blocks.

\section{Imaging Methods}

Scanning was performed on a 3T Tim Trio Scanner (Siemens, Erlangen, Germany), using a fast sparse imaging protocol. Each trial consisted of a 1.4-sec silence and 2-sec acquisition, with sounds played within the silent periods to minimize interference of scanner noise with auditory processing. Gradient-echo imaging (EPI) sequence parameters were as follows: repetition time $=3.4 \mathrm{sec}$, acquisition time $=2 \mathrm{sec}$, echo time $=30 \mathrm{msec}$, flip angle $=78^{\circ}$, matrix size $=64 \times 64$. The functional images consisted of 32 slices covering the whole brain (slice thickness $=3 \mathrm{~mm}$, 
in-plane resolution $=3 \times 3 \mathrm{~mm}$, interslice distance $=$ $0.75 \mathrm{~mm}$ ). MPRAGE T1-weighted scans were acquired for anatomical localization.

\section{Data Analysis}

\section{Preprocessing}

Imaging data were analyzed using SPM8 software (Wellcome Department of Imaging Neuroscience, London, United Kingdom). For both univariate and multivariate analyses, images were corrected for slice timing and spatially realigned to the first image using sinc interpolation. The EPI images were coregistered to the structural T1 images using standard coregistration procedures. The structural MRI was normalized to the 152-subject T1 template of the Montreal Neurological Institute (MNI). The resulting transformation parameters were applied to the coregistered EPI images. During the spatial normalization, images were resampled with a spatial resolution of $2 \times 2 \times 2 \mathrm{~mm}^{3}$.

\section{Univariate Analysis}

For the univariate analysis, normalized images were spatially smoothed by convolution of a 10-mm FWHM Gaussian kernel and globally normalized. Single-subject statistical comparisons were computed by using the general linear model. Low-frequency noise was removed by applying a high-pass filter of $128 \mathrm{sec}$. The neural response for each event type was modeled with the canonical hemodynamic response function. Motion regressors were included as covariates of no interest to account for any residual movement effects. Group data were analyzed using random effects analysis. Furthermore, we examined the realignment parameters for all participants to ensure head motion was not in excess of $4 \mathrm{~mm}$ in any direction during the test sessions. Whole-brain analysis results are displayed after controlling for false discovery rate (FDR) at 0.05 for multiple comparisons at cluster level. Stereotaxic coordinates for voxels with maximal $t$ values within activation clusters are reported in the MNI standard space.

Consistent with our predictions and previous work (Bozic et al., 2010; Tyler \& Marslen-Wilson, 2008; Binder et al., 1997), a bilateral frontotemporal VOI was selected for both univariate and multivariate analyses. Using PickAtlas, a mask was created, including bilateral temporal lobes (superior, middle, and inferior temporal gyri, including temporal poles), angular gyrus, inferior frontal gyrus (IFG; pars opercularis, BA 44; pars triangularis, BA 45; pars orbitalis, BA 47), and the anterior cingulate. All results were assessed and displayed using this mask.

\section{Multivariate Analysis}

For multivariate representational similarity analysis (RSA), the analysis was carried out in subject native space, using realigned, unsmoothed, and unnormalized functional data, which were coregistered with the MPRAGE of each subject. Data were analyzed using the general linear model to create parameter estimates for each item, which were used to compute $t$-statistic maps. Data were then extracted for each participant individually using a "sphere of information" searchlight approach (Nili et al., 2014; Kriegeskorte et al., 2008). A roaming spherical searchlight with 5-mm radius (Kriegeskorte et al., 2008) was moved throughout the gray matter to extract continuous, voxel-by-voxel maps of word-elicited activation values. To achieve maximal sensitivity to our experimental manipulations, this analysis was based on single items, with each experimental word modeled as a condition and associated with a separate hemodynamic predictor. The correlation distances (1 Pearson's correlation) between the response patterns for each word paired with every other word were expressed as representational dissimilarity matrices (RDMs), which are symmetric about a diagonal of zeros (Kriegeskorte et al., 2008). These brain data RDMs were then correlated with theoretical model RDMs (using Spearman's rank correlation) at each brain location. The resulting maps of $r$ values for each participant and model were normalized onto the MNI template and entered into a group level random-effects analysis using permutation-based nonparametric statistics in SNPM (http://www2.warwick.ac.uk/ fac/sci/statistics/staff/academic-research/nichols/software/ snpm) to test for positive correlations between the model RDMs and brain data RDMs. FDR correction at 0.05 for multiple comparisons across voxels and number of models was applied. Ten thousand permutations were used in the analysis.

Table 2. Activation Coordinates for General Lexical Processing

\begin{tabular}{lccrrr}
\hline & & & \multicolumn{3}{c}{ Coordinates } \\
\cline { 5 - 6 } Regions & Cluster & & $x$ & $y$ & $z$ \\
\hline All words-MuR & Voxel Z & $x$ & & & \\
L MTG (BA 21) & 5182 & 6.62 & -62 & -12 & -2 \\
L STG (BA 22) & & 6.14 & -64 & -10 & 2 \\
L MTG (BA 21) & & 5.90 & -64 & -28 & 4 \\
R MTG (BA 21) & 3619 & 6.62 & 68 & -26 & 0 \\
R STG (BA 22) & & 6.61 & 62 & -10 & 0 \\
R superior temporal & & 6.30 & 54 & 14 & -18 \\
$\quad$ pole (BA 22) & & & & & \\
L IFG (BA 47) & 140 & 4.58 & -42 & 30 & -6 \\
L IFG (BA 45) & & 4.27 & -52 & 12 & 22 \\
L IFG (BA 44) & & 3.45 & -54 & 30 & 18 \\
R IFG (BA 47) & 267 & 4.29 & 62 & 14 & 26 \\
R IFG (BA 45) & & 4.10 & 60 & 18 & 26 \\
R rolandic 0perculum & & 3.48 & 62 & 6 & 16 \\
\hline
\end{tabular}




\section{RESULTS}

\section{Univariate Analyses}

To assess the regions involved in general lexical processing, we contrasted all words against the MuR baseline (see Table 2). This comparison showed activations in bilateral middle and superior temporal gyri (MTG, STG), extending to LIFG (BA 44, 45, 47), and right inferior frontal gyrus (RIFG; BA 45, 47), broadly consistent with the previous literature (e.g., Bozic, Szlachta, et al., 2013; Bozic, Tyler, et al., 2013; Bozic et al., 2010; Binder et al., 1997).

We then examined lexical processes specific to individual experimental conditions, contrasting each condition against MuR separately. Relative to baseline, transparent productive words engaged bilateral temporal regions (Figure 1A; Table 3A), with no sign of selective LIFG activation, consistent with previous univariate results for English and Polish (Bozic, Szlachta, et al., 2013; Bozic, Tyler, et al., 2013). Transparent nonproductive words activated bilateral temporal regions and LIFG BA 47 (Figure 1B; Table 3B). This region of LIFG is generally not associated with combinatorial morphosyntax. Opaque productive words activated bilateral MTG, with activation extending to right STG, left superior temporal pole, and LIFG
BA 44, 45 (Figure 1C; Table 3C). Opaque nonproductive words activated large extents of bilateral temporal and inferior frontal regions (BA 44, 45, 47; Figure 1D; Table 3D). Derivationally simple words activated the frontotemporal system bilaterally (Figure 1E; Table 3E), but with substantially stronger activation of LIFG (BA 44, 45, 47) than of RIFG (BA 44).

We then turned to a more global set of comparisons, designed to pull out the effects of the major dimensions of transparency and productivity as they varied across the four factorial conditions (1-4). These show that the dominant univariate activation effects are for the opaque items, most strongly for the opaque nonproductive condition, and with no evidence for selective LIFG engagement. First, we compared all opaque words with all transparent words, collapsing across productivity. Here we see (Figure 2A; Table 4A) stronger bilateral frontotemporal activation for opaque words overall, with similar levels bilaterally of STG and MTG activation, and smaller bilateral effects in BA 44 and 45 . We then unpacked these results to explore the effects of transparency and opacity on responses to nonproductive and productive words separately. No significant differences were seen for the contrast between opaque and transparent productive words. Opaque nonproductive words, however, elicited

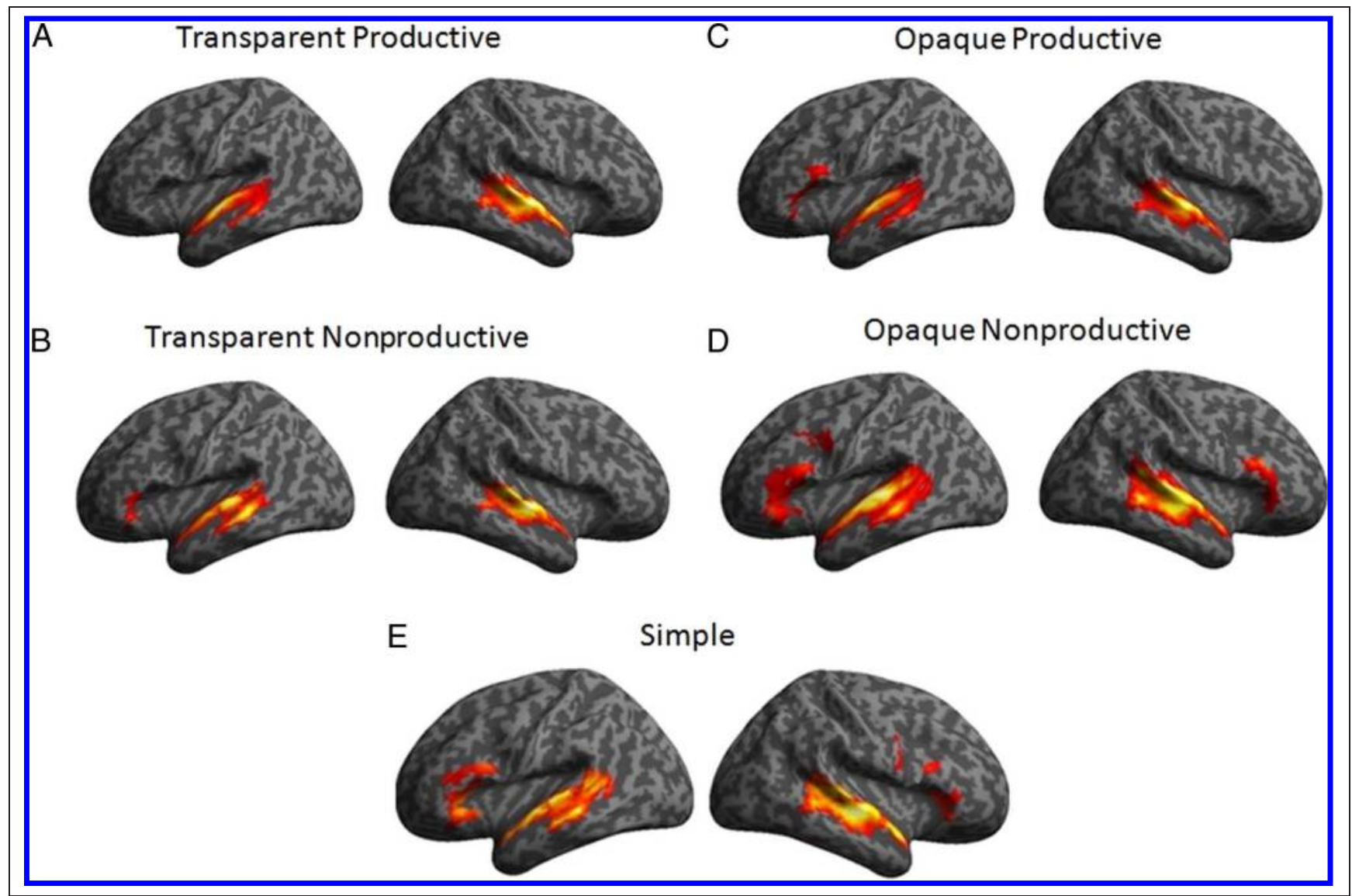

Figure 1. Univariate results showing activations for each experimental condition contrasted against the MuR baseline: (A) Transparent Productive words, (B) Transparent Nonproductive words, (C) Opaque Productive words, (D) Opaque Nonproductive words, and (E) Simple words. Results are shown at a threshold of $p<.001$ uncorrected, with cluster level correction for FDR 0.05 . 
Table 3. Activation Coordinates for Five Groups of Derivationally Complex and Simple Words

\begin{tabular}{|c|c|c|c|c|c|}
\hline \multirow[b]{2}{*}{ Regions } & \multirow{2}{*}{$\begin{array}{l}\text { Cluster } \\
\text { Extent }\end{array}$} & \multirow{2}{*}{$\begin{array}{c}\text { Voxel } \\
Z\end{array}$} & \multicolumn{3}{|c|}{ Coordinates } \\
\hline & & & $x$ & $y$ & $z$ \\
\hline
\end{tabular}

(A) Transparent Productive-MuR

$\begin{array}{llllrr}\text { L MTG (BA 21) } & 2302 & 6.44 & -62 & -12 & 0 \\ \begin{array}{c}\text { L superior temporal } \\ \text { pole (BA 38) }\end{array} & & 4.56 & -56 & 10 & -12 \\ \text { L STG (BA 22) } & & 3.40 & -66 & -32 & 20 \\ \text { R STG (BA 22) } & 3109 & 6.37 & 64 & -10 & -2 \\ \text { R MTG (BA 22) } & & 6.27 & 68 & -24 & -2 \\ \text { R STG (BA 22) } & 5.57 & 60 & -2 & -8\end{array}$

(B) Transparent Nonproductive-MuR

$\begin{array}{lrrrrr}\text { L MTG (BA 21) } & 2053 & 6.15 & -62 & -30 & 2 \\ \text { L MTG (BA 21) } & & 5.81 & -64 & -40 & 2 \\ \text { L MTG (BA 21) } & & 5.74 & -56 & -24 & -2 \\ \text { R STG (BA 22) } & 2173 & 6.40 & 62 & -12 & 0 \\ \text { R MTG (BA 22) } & & 5.75 & 68 & -26 & 0 \\ \text { R MTG (BA 22) } & & 5.54 & 58 & -30 & 2 \\ \text { L IFG (BA 47) } & 353 & 4.30 & -46 & 28 & -6 \\ & & & & & \\ \text { (C) Opaque Productive-MuR } & & & & \\ \text { L MTG (BA 22) } & 3183 & 6.74 & -62 & -12 & 0 \\ \text { L superior temporal } & & 4.96 & -52 & 8 & -14 \\ \text { pole (BA 38) } & & & & & \\ \text { L IFG (BA 44) } & & 4.17 & -52 & 12 & 20 \\ \text { L IFG (BA 45) } & & 4.02 & -42 & 26 & -2 \\ \text { R STG (BA 21) } & 2717 & 6.61 & 64 & -12 & 2 \\ \text { R STG (BA 21) } & & 5.97 & 66 & -28 & 2 \\ \text { R STG (BA 21) } & & 5.64 & 60 & -18 & -6\end{array}$

(D) Opaque Nonproductive-MuR

\begin{tabular}{lrrrrr} 
L STG (BA 21) & 6383 & 7.18 & -62 & -10 & 2 \\
L MTG (BA 22) & & 6.85 & -62 & -28 & 4 \\
L superior temporal & & 5.48 & -56 & 12 & -12 \\
pole (BA 38) & & & & \\
L IFG (BA 44) & 4.76 & -50 & 14 & 22 \\
L IFG (BA 47) & & 4.95 & -48 & 32 & -5 \\
L IFG (BA 45) & & 4.32 & -40 & 28 & 8 \\
R STG (BA 21) & 5117 & 6.83 & 70 & -24 & 2 \\
R MTG (BA 22) & & 6.66 & 56 & -44 & 8 \\
\hline
\end{tabular}

Table 3. (continued)

\begin{tabular}{|c|c|c|c|c|c|}
\hline \multirow[b]{2}{*}{ Regions } & \multirow{2}{*}{$\begin{array}{l}\text { Cluster } \\
\text { Extent }\end{array}$} & \multirow{2}{*}{$\begin{array}{c}\text { Voxel } \\
Z\end{array}$} & \multicolumn{3}{|c|}{ Coordinates } \\
\hline & & & $x$ & $y$ & $z$ \\
\hline R STG (BA 21) & & 6.61 & 62 & -8 & ( \\
\hline R IFG (BA 44) & & 5.51 & 52 & 24 & 24 \\
\hline R IFG (BA 47) & & 3.96 & 52 & 28 & -6 \\
\hline (E) Simple-MuR & & & & & \\
\hline L MTG (BA 22) & 4382 & 6.60 & -60 & -14 & -4 \\
\hline L MTG (BA 22) & & 5.64 & -66 & -38 & 4 \\
\hline $\begin{array}{l}\text { L superior temporal } \\
\text { pole (BA 38) }\end{array}$ & & 5.25 & -56 & 12 & -14 \\
\hline L IFG (BA 47) & & 4.68 & -36 & 26 & -6 \\
\hline L IFG (BA 45) & & 4.37 & -44 & 12 & 26 \\
\hline L IFG (BA 44) & & 4.18 & -48 & 10 & 22 \\
\hline R MTG (BA 22) & 3726 & 5.62 & 58 & -22 & -4 \\
\hline $\begin{array}{l}\text { R superior temporal } \\
\text { pole (BA 38) }\end{array}$ & & 5.85 & 62 & -12 & -4 \\
\hline R STG (BA 21) & & 5.71 & 54 & 6 & -16 \\
\hline R IFG (BA 44) & 410 & 5.80 & 62 & 16 & 20 \\
\hline R IFG (BA 44) & & 5.73 & 60 & 16 & 28 \\
\hline R IFG (BA 45) & & 4.32 & 48 & 20 & 22 \\
\hline
\end{tabular}

much stronger activation than transparent nonproductive words (Figure 2B; Table 4B), with strong bilaterally balanced effects in left and right STG, MTG, BA 44, and precentral gyrus.

Comparisons between nonproductive and productive forms (collapsing across transparency) showed no activation differences. Breaking down these results for transparent and opaque words separately, we found no differences between transparent nonproductive and productive words. Opaque nonproductive forms, in contrast, exhibited increased activation compared with opaque productive forms in temporal cortex bilaterally, with smaller effects in right BA 47 and BA 45 (Figure 2C; Table 4C).

In a final univariate examination of the key dimensions manipulated in this study-semantic transparency and suffix productivity in relation to cohort-based lexical competition-we ran a series of correlational parametric modulator analyses, conducted at the individual item rather than condition level, and separately for the opaque and for the transparent word sets. For these analyses, main effects of the three modulator variables (transparency, productivity, and competition ratio) were only seen for the opaque words (as plotted in Figure 3). We focus on the results for these opaque sets first.

For lexical competition, defined as the ratio between the log frequencies of the suffixed morphological variants 
Figure 2. Univariate results for global comparisons between conditions: (A) all Opaque words versus all Transparent words, (B) Opaque

Nonproductive words compared with Opaque Productive words, and (C) Opaque Nonproductive words compared with Transparent Nonproductive words. Results are shown at a threshold of $p<.001$ uncorrected, with cluster level correction for FDR 0.05 .

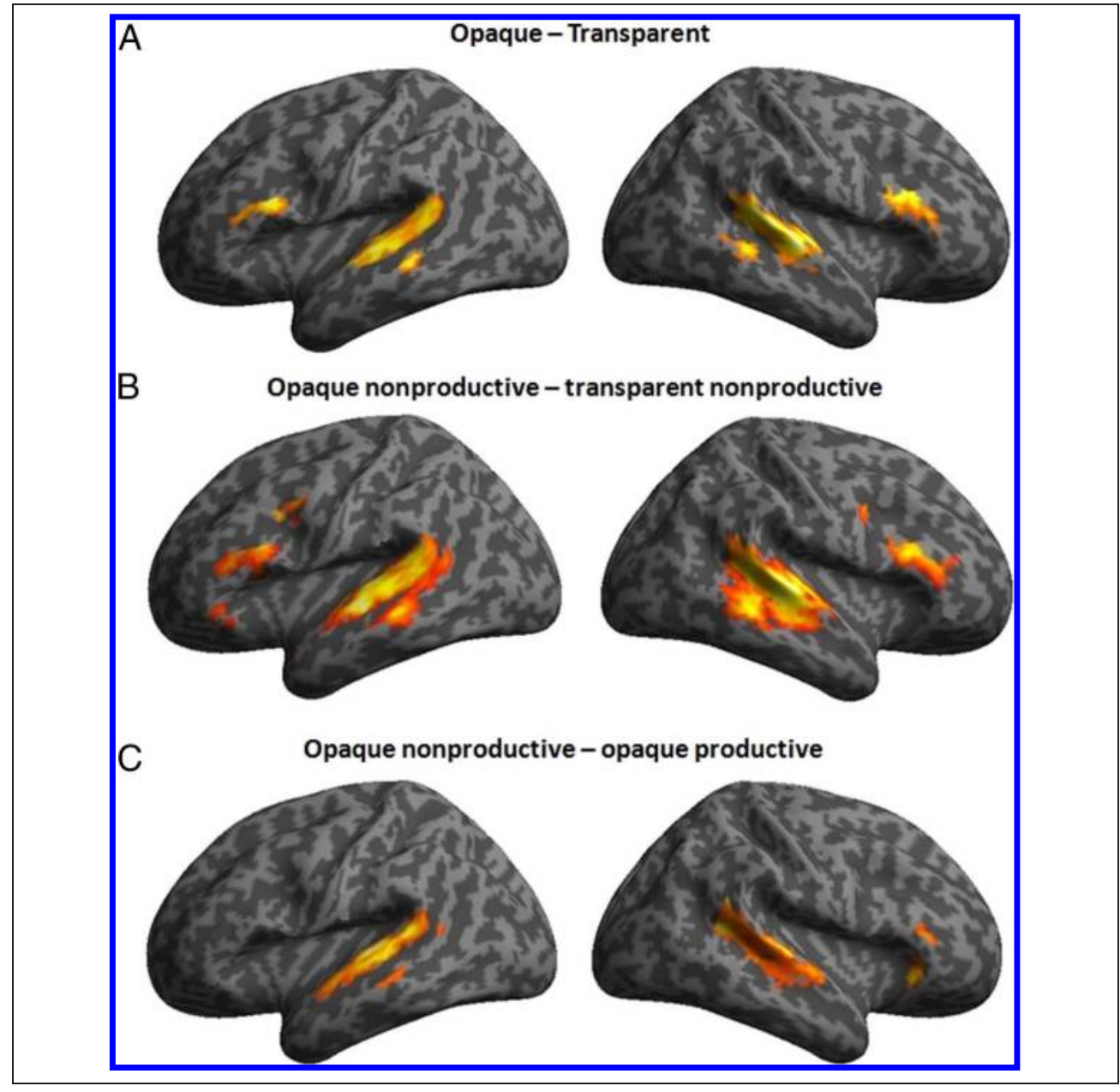

of the embedded stem or pseudostem and the log lemma frequency of the whole form, increased competition (i.e., higher relative frequency for the embedded stem) led to increased activation in MTG (BA 21) bilaterally for the opaque forms, although the LH effects were only marginally significant (cluster level uncorrected $p<.01$ ). This is consistent with the results seen for Polish (Bozic, Szlachta, et al., 2013), where lexical competition effects were also only significant for the opaque items. Effects were similar for semantic relatedness, with bilateral activation in MTG (BA 21), which again was only marginally significant in the LH. These effects broadly overlap with the lexical competitor effects in bilateral MTG. The third variable, of suffix productivity, showed marginally significant $(p<.01)$ increases in activation associated with decreased productivity. These effects, where lower suffix productivity is associated with higher levels of neural activation, were seen in bilateral inferior frontal regions (left insula, left BA 44 and BA 47, right BA 45) and in the left inferior temporal gyrus.

The trends seen in these parametric modulator results are consistent with the preceding subtractive analyses in suggesting that semantic transparency is the primary variable determining the representational and processing relationship between derivationally complex forms and their onset-embedded stems (or pseudostems). Only the opaque forms show significant across-the-board effects of lexical competition, consistent with the view that the increased activation for these forms reflects cohort competition between the separate lexical representations for the derived forms and for their embedded stems or pseudostems. This competition between cohort members (e.g., between ventura and vento) is amplified by the presence of a nonproductive suffix and by decreased semantic relatedness between the whole form and its onset-embedded competitor.

Turning to the transparent items, these show no overall effects for the main modulator variables. Differences only start to emerge when we break down the transparent sets according to productivity. For the transparent productive words, such as libreria or guidatore, there is still no evidence for competition effects, similar to previous results for English and Polish (Bozic, Szlachta, et al., 2013; Bozic, Tyler, et al., 2013). The transparent nonproductive words (such as pineta), in contrast, diverge from the results for the productive words, consistent with the univariate English results for forms like warmth. Bilateral temporal effects are seen both for semantic relatedness and for lexical competition, although in the opposite direction to results for the opaque items. Increased semantic 
Table 4. Activation Coordinates for Overall Contrasts between Opaque and Transparent Words

\begin{tabular}{lccrrr}
\hline & & Cluster & Voxel & \multicolumn{2}{c}{ Coordinates } \\
\cline { 5 - 6 } Regions & Extent & $Z$ & $x$ & $y$ & $z$ \\
\hline (A) All Opaque-All Transparent & & & & \\
L STG (BA 21) & 1450 & 5.07 & -60 & -14 & 2 \\
L STG (BA 21) & & 4.89 & -54 & -22 & 4 \\
L MTG (BA 22) & & 4.40 & -60 & -42 & 8 \\
R IFG (BA 45) & 607 & 4.67 & 44 & 30 & 10 \\
R IFG (BA 44) & & 4.59 & 58 & 20 & 28 \\
R IFG (BA 45) & & 4.46 & 48 & 24 & 24 \\
R MTG (BA 22) & 1666 & 4.63 & 60 & -34 & 4 \\
R STG (BA 21) & & 4.63 & 64 & -20 & 8 \\
R STG (BA 21) & & 4.52 & 50 & -42 & 14 \\
L IFG (BA 44) & & 4.21 & -44 & 8 & 24 \\
L IFG (BA 44) & 224 & & & \\
L IFG (BA 44) & & 4.09 & -38 & 4 & 30 \\
L IFG (BA 45) & & 3.81 & -54 & 12 & 28 \\
L IFG (BA 45) & & 4.16 & -40 & 30 & 8 \\
& & 3.25 & -48 & 22 & 18 \\
& & & &
\end{tabular}

(B) Opaque Nonproductive-Transparent Nonproductive

$\begin{array}{lrrrrr}\text { R STG (BA 21) } & 3152 & 5.74 & 68 & -26 & 6 \\ \text { R STG (BA 21) } & & 5.10 & 48 & -24 & 2 \\ \text { R STG (BA 21) } & & 5.05 & 58 & -24 & 4 \\ \text { L MTG (BA 22) } & 2613 & 5.68 & -48 & -22 & 0 \\ \text { L MTG (BA 22) } & & 5.36 & -54 & -16 & -2 \\ \text { L STG (BA 21) } & & 4.96 & -52 & -40 & 14 \\ \text { R IFG (BA 45) } & 820 & 4.91 & 56 & 22 & 22 \\ \text { R IFG (BA 45) } & & 4.28 & 46 & 28 & 14 \\ \text { R precentral gyrus (BA 6) } & & 4.27 & 52 & 14 & 38 \\ \text { L IFG (BA 45) } & 796 & 4.60 & -44 & 12 & 26 \\ \text { L precentral gyrus (BA 6) } & & 4.40 & -38 & 2 & 36 \\ \text { L IFG (BA 45) } & & 4.27 & -44 & 26 & 12\end{array}$

(C) Opaque Nonproductive-Opaque Productive

\begin{tabular}{crrrrr} 
L STG (BA 21) & 1597 & 5.20 & -56 & -26 & 4 \\
L MTG (BA 22) & & 4.58 & -66 & -44 & 8 \\
L MTG (BA 22) & & 4.45 & -64 & -54 & 10 \\
R MTG (BA 22) & 1477 & 5.08 & 44 & -46 & 20 \\
R STG (BA 21) & & 5.00 & 70 & -24 & 8 \\
R STG (BA 21) & & 3.81 & 60 & -8 & -6 \\
R IFG (BA 47) & 265 & 4.43 & 40 & 28 & -6 \\
R IFG (BA 45) & & 4.01 & 46 & 30 & 10 \\
\hline
\end{tabular}

relatedness is linked to increased activation in left STG and right MTG, whereas decreased lexical competition is linked to increased activation in left inferior temporal gyrus and right MTG. This suggests that these effects are not driven by cohort competition in the same way as for the opaque items. We return to these contrasts in the Discussion section below.

\section{Multivariate Analyses}

Representational similarity analysis (RSA) is a multivariate pattern analysis technique that can directly test theoretical claims about the nature and content of neural computations, sampled on a brain-wide basis using a "searchlight" procedure (Nili et al., 2014; Kriegeskorte et al., 2008). To do this requires the development of model RDMs to represent hypotheses about the role of different morpholexical variables in the brain's response to the experimental words (see Figure 4). To increase the power and sensitivity of these analyses, we constructed the model RDMs and the corresponding data RDMs on a "single trial" basis, where each item is entered individually into the dissimilarity matrix, rather than examining effects at a condition level averaging across items.

The first set of model RDMs (Figure 4A) tested for patterns of activation related to cohort-based perceptual competition, defined as the ratio between the log frequencies of the embedded stem and the whole form lemma. The All Words Lexical Competition RDM expresses the pairwise relationship of these values for every word in Conditions $1-4$ of the experiment. This gives a $320 \times 320$ data matrix (Figure 4A.1). This reduces to two smaller matrices, each $160 \times 160$ cells, for the transparent words alone (Figure 4A.2) and for the opaque words alone (Figure 4A.3).

The results (see Figure 5A and Table 5A) for the All Words set show significant model fit in bilateral STG and MTG, in right and left cingulate, and with relatively weak bilateral IFG effects. Breaking the data down into Opaque and Transparent subsets, no Lexical Competition effects were seen for the Transparent words, whereas effects for the Opaque forms (Table 5B and Figure 5B) were seen in bilateral STG. In further analyses, partitioning the data according to productivity, no significant model fit was seen.

A second set of model RDMs (Figure 4B) tested for effects of semantic relatedness between the derived words and their embedded stems based on native speakers' judgments about the link between their meanings. The resulting $320 \times 320$ All Words model RDM (Figure 4B.1) shows bilateral temporal and inferior frontal fit, as well as large clusters in right and left fusiform (Figure 6A and Table 6A). In subanalyses conducted on the Transparent and the Opaque model RDMs separately (Figure 4B.2 and B.3), no effects were seen for variations in semantic relatedness within the set of Transparent words, similarly to the Lexical Competition results. There were strong effects for the Opaque 
Figure 3. Parametric

modulation results for the

Opaque word sets: (A) Semantic

Relatedness (in red), (B) Lexical

Competition (in green), and

(C) Suffix Productivity (in blue).

Results are shown at a threshold

of $p<.001$ uncorrected, and at

a more lenient threshold of

$p<.01$ for Suffix Productivity.

Only left middle temporal

activations to Semantic

Relatedness and Lexical

Competition survived

correction for FDR 0.05 .

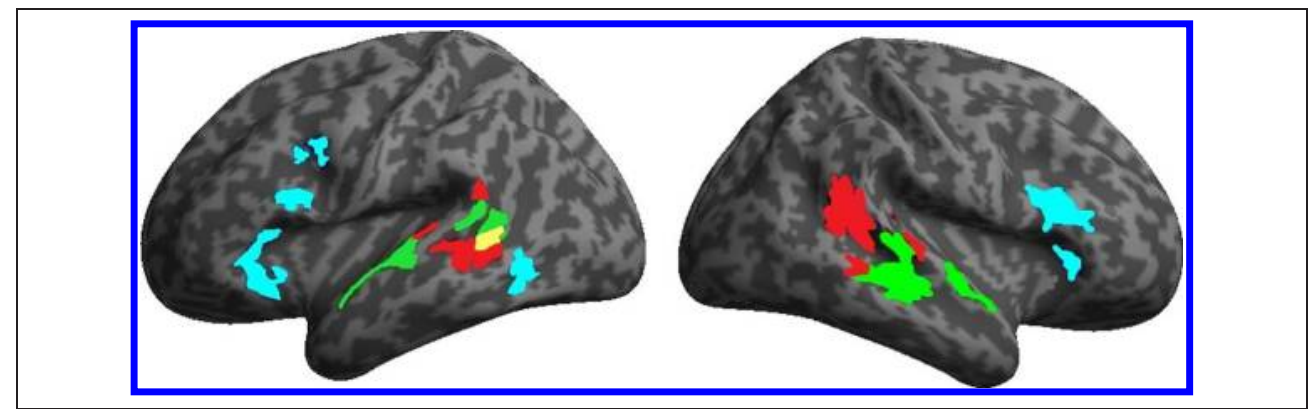

words (Figure 6B and Table 6B), with these being substantially larger in Opaque Productive words (Figure 6C and Table 6C) than in Opaque Nonproductive words (Figure 6D and Table 6D).
The final set of model RDMs (Figure 4C) tested for effects of suffix productivity, quantified (as described earlier) in terms of the Baayen and Lieber (1991) bapax legomena-based procedure. Again, we constructed an

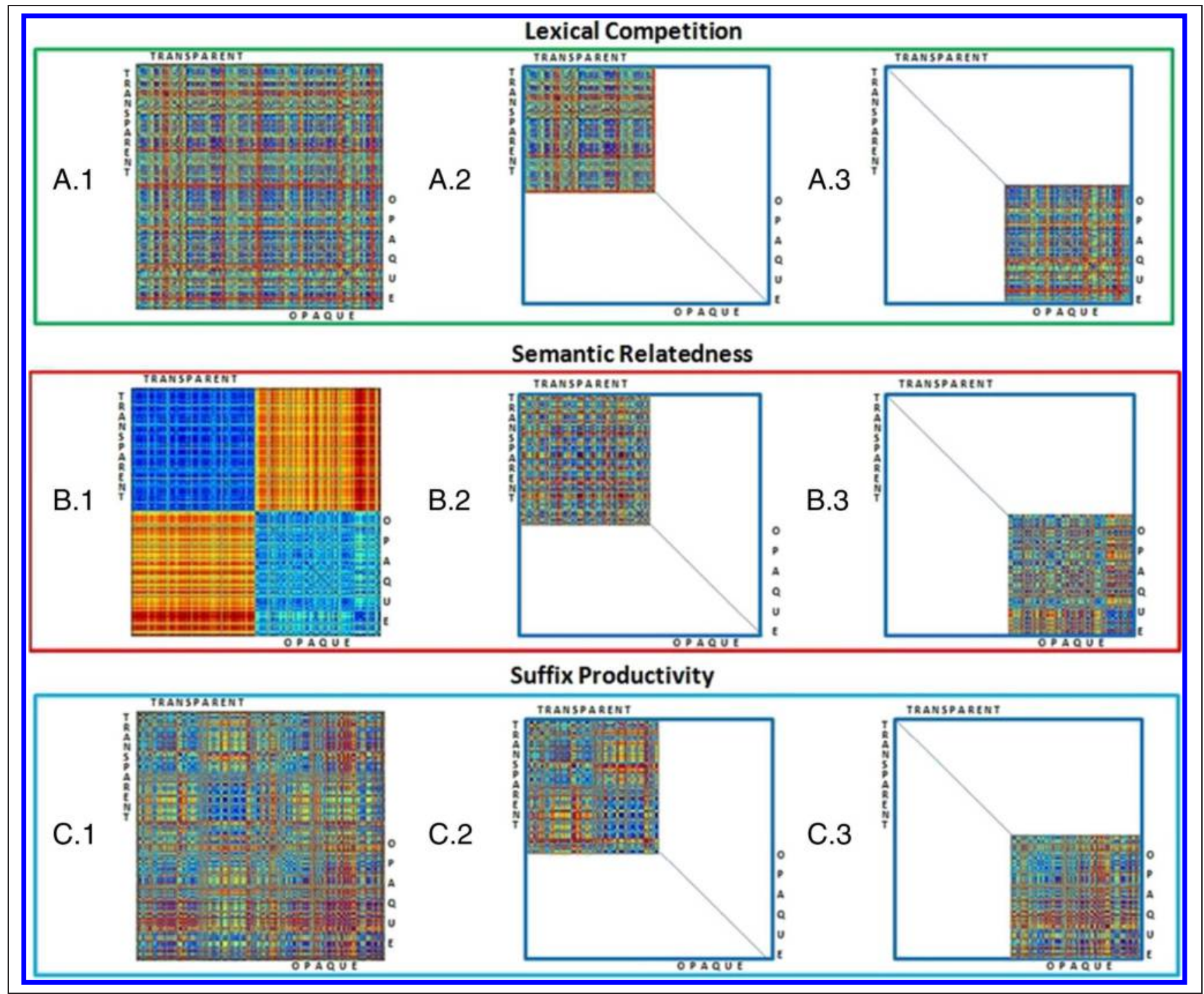

Figure 4. The six model RDMs used in the RSA analyses: (A) Lexical Competition RDMs for (A.1) All words, (A.2) Transparent words, and (A.3) Opaque words; (B) Semantic Relatedness RDMs for (B.1) All words, (B.2) Transparent words, and (B.3) Opaque words; and (C) Suffix Productivity RDMs for (C.1) All words, (C.2) Transparent words, and (C.3) Opaque words. 


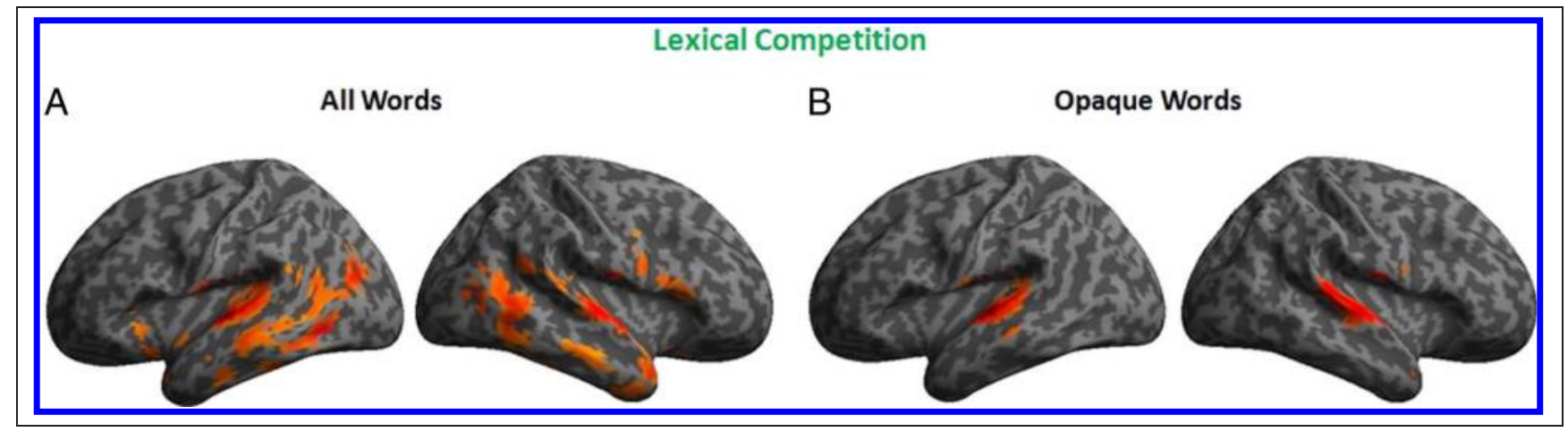

Figure 5. RSA Lexical Competition analyses: Brain areas showing significant model fit for (A) All words and (B) Opaque words. All results are significant at FDR 0.05 .

All Words $320 \times 320$ model RDM (Figure 4C.1), and two $160 \times 160$ submatrices for Transparent and Opaque Words separately (Figure 4C.2 and C.3). In contrast to the results for the Lexical Competition and Semantic Relatedness analyses, we saw no significant model fit for the
All Words model RDM nor for the Opaque Words submatrix. Instead we see significant results for the Transparent Words model RDM (Figure 7A and Table 7A), with strong bilateral temporal effects in STG (BA 21), extending into MTG and temporal pole in the RH and with significant

Table 5. RSA Analyses for Lexical Competition

\begin{tabular}{|c|c|c|c|c|c|c|}
\hline \multirow[b]{2}{*}{ Regions } & \multirow[b]{2}{*}{ Cluster Extent } & \multirow[b]{2}{*}{ Voxel Level p } & \multirow[b]{2}{*}{ Pseudo- $t$} & \multicolumn{3}{|c|}{ Coordinates } \\
\hline & & & & $x$ & $y$ & $z$ \\
\hline \multicolumn{7}{|c|}{ (A) Lexical Competition (All Words) } \\
\hline L STG (BA 21) & 953 & .0043 & 6.98 & -60 & -16 & 6 \\
\hline L MTG (BA 22) & & .0043 & 4.77 & -42 & -58 & -4 \\
\hline R STG (BA 21) & 818 & .0043 & 4.99 & 60 & -13 & 6 \\
\hline R MTG (BA 22) & & .0074 & 3.91 & 57 & -55 & 2 \\
\hline R STG (BA 21) & & .0043 & 3.75 & 60 & -52 & 21 \\
\hline $\mathrm{R}$ anterior cingulate (BA 24) & 371 & .0060 & 4.86 & 3 & 23 & 29 \\
\hline $\mathrm{R}$ anterior cingulate (BA 24) & & .0199 & 3.81 & 9 & 38 & 18 \\
\hline L anterior cingulate (BA 24) & & .0199 & 3.31 & -3 & 35 & 14 \\
\hline R fusiform (BA 37) & 110 & .0194 & 3.10 & 33 & -55 & -16 \\
\hline R fusiform (BA 20) & & .0103 & 3.04 & 39 & -31 & -20 \\
\hline L IFG (BA 47) & 29 & .0263 & 3.15 & -18 & 8 & -20 \\
\hline $\mathrm{L}$ insula & & .0254 & 2.51 & -27 & 23 & -5 \\
\hline L inferior temporal gyrus (20) & & .0377 & 3.09 & -54 & -16 & -28 \\
\hline R IFG (BA 44) & 133 & .0304 & 3.02 & 51 & 20 & 10 \\
\hline R precentral gyrus (BA 6) & & .0361 & 2.27 & 54 & 2 & 36 \\
\hline \multicolumn{7}{|c|}{ (B) Lexical Competition (Opaque Words) } \\
\hline L STG (BA 21) & 346 & .0043 & 6.55 & -60 & -16 & 6 \\
\hline L STG (BA 21) & & .0064 & 3.93 & -42 & -34 & 14 \\
\hline R STG (BA 21) & 302 & .0043 & 5.67 & 63 & -10 & 6 \\
\hline R STG (BA 21) & & .0043 & 5.02 & 63 & -25 & 10 \\
\hline
\end{tabular}

Coordinates and voxel level peak significance values $(p)$ for each activation cluster. 
A

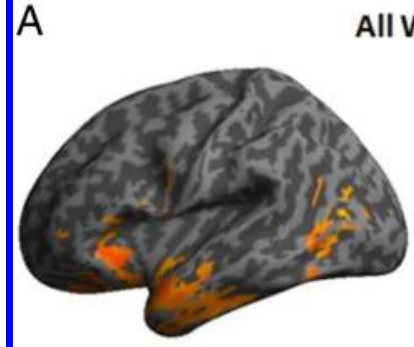

All Words

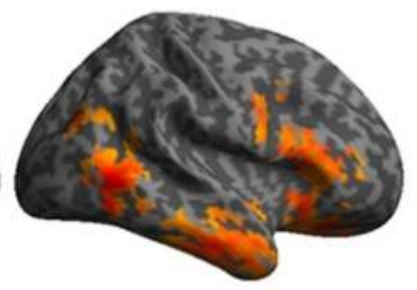

Opaque Productive Words

C
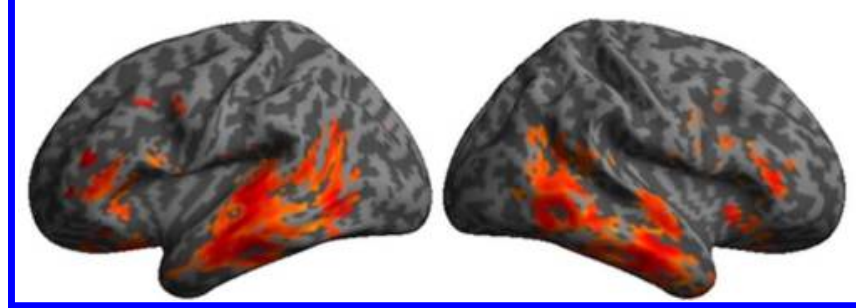

B

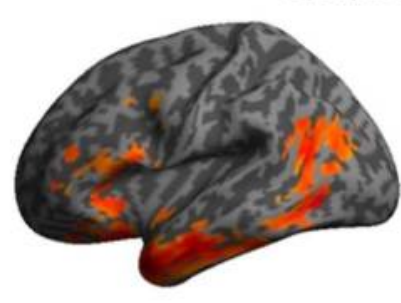

Opaque Words

D Opaque Nonproductive Words

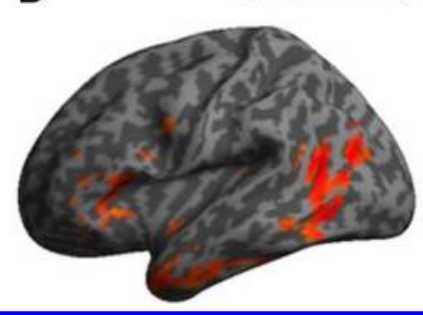

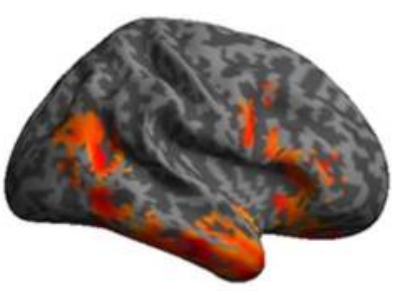

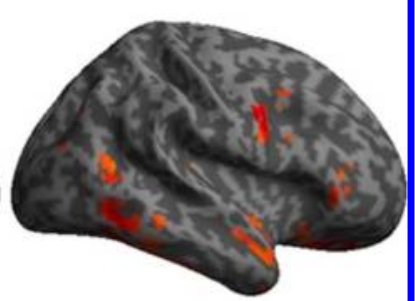

Figure 6. RSA Semantic Relatedness analyses: Brain areas showing significant model fit for (A) All words, (B) Opaque words, (C) Opaque Productive words, and (D) Opaque Nonproductive words. All results are significant at FDR 0.05.

model fit in LIFG (BA 44) but not in RIFG. This is the first evidence we have seen for selective engagement of the left perisylvian language system by derived forms. A further breakdown of the Transparency model RDM into two $80 \times 80$ Productive and Nonproductive matrices revealed no effects for nonproductive words and reduced effects for transparent productive words, restricted to temporal regions bilaterally (Figure $7 \mathrm{~B}$ and Table 7B).

\section{DISCUSSION}

In the context of the incomplete but intriguing results from previous cross-linguistic neuroimaging studies, this research used a combination of univariate and multivariate methods to probe the respective roles of semantic transparency and affix productivity in determining whether derivationally complex word forms are decompositionally represented and to establish which brain regions are primarily involved in the perceptual interpretation of these forms.

The primary finding is a defining role for semantic transparency-though significantly modulated by affix productivity - in determining the underlying representation of derivationally complex forms. The opaque and transparent sets, separated on the basis of their judged semantic relatedness, interacted differently with the variables of competition, semantic relatedness, and productivity. This generated three main classes of effects, which are discussed in the following sections.

\section{Opaque Forms}

For the opaque forms (e.g., ventura, "destiny"), the results consistently indicate that these are represented as "whole forms," defined as a separate lexical entry (or lexeme) with no internal representation of morphemic structure, such that the onset-embedded unrelated stem or pseudostem constitutes a second, different lexeme (e.g., vento, "wind"). This second lexeme acts as a strong cohort competitor, potentially delaying the recognition of the derived form, in a manner similar to the cohort competition effects seen for morphologically simple forms with onset-embedded competitors (e.g., ram/ ramp; Szlachta et al., 2012; Bozic et al., 2010). The higher the frequency of the onset-embedded stem or pseudostem, the stronger a competitor it will be for the derived form that the participant is actually hearing. In the univariate analyses (Figure 3), increases in activity associated with increased levels of lexical competition are only seen for the opaque conditions. Consistent with this, in the RSA analyses only the lexical competition model specific to the opaque words fits the patterns of brain activity (Figure 5; Table 5).

The uniformly bilateral distribution of these competition effects and the absence of selective left perisylvian activation indicate that the processing domain for the perceptual analysis of the opaque forms is the domain-general bihemispheric system (Marslen-Wilson et al., 2014; Bozic et al., 2010). The RSA results, furthermore, show model fit in bilateral dorsal IFG (BA 44, 45) —associated with the selection between automatically retrieved competitors (Zhuang, Tyler, Randall, Stamatakis, \& Marslen-Wilson, 2014; Thompson-Schill, D'Esposito, \& Kan, 1999)—as well as in ACC (Botvinick, Cohen, \& Carter, 2004) and middle/posterior temporal regions (Bokde, Tagamets, Friedman, \& Horwitz, 2001). Activity in all these regions has been found in association with increases in lexical competition (e.g., Bozic, 
Table 6. RSA Analyses for Semantic Relatedness

\begin{tabular}{|c|c|c|c|c|c|c|}
\hline \multirow[b]{2}{*}{ Regions } & \multirow[b]{2}{*}{ Cluster Extent } & \multirow[b]{2}{*}{ Voxel Level p } & \multirow[b]{2}{*}{ Pseudo-t } & \multicolumn{3}{|c|}{ Coordinates } \\
\hline & & & & $x$ & $y$ & $z$ \\
\hline \multicolumn{7}{|l|}{ (A) Semantic Relatedness (All Words) } \\
\hline L fusiform (BA 20) & 1034 & .0032 & 5.13 & -18 & -37 & -16 \\
\hline L fusiform (BA 20) & & .0023 & 4.51 & -36 & -16 & -24 \\
\hline R fusiform (BA 20) & 724 & .0023 & 5.39 & 39 & -16 & -28 \\
\hline $\mathrm{R}$ inferior temporal gyrus (BA 20) & & .0023 & 4.78 & 54 & -16 & -28 \\
\hline R IFG orbitalis (BA 47) & 678 & .0023 & 5.06 & 27 & 29 & -12 \\
\hline R IFG orbitalis (BA 47) & & .0023 & 4.55 & 18 & 21 & -20 \\
\hline $\mathrm{R}$ anterior cingulate (BA 32) & 483 & .0023 & 4.85 & 9 & 35 & 29 \\
\hline R MTG (BA 22) & 365 & .0023 & 5.67 & 57 & -58 & -1 \\
\hline L inferior temporal gyrus (BA 20) & 134 & .0079 & 3.84 & -51 & -64 & -5 \\
\hline L MTG (BA 22) & & .0201 & 3.23 & -40 & -61 & -5 \\
\hline R MTG (BA 22) & 86 & .0182 & 2.67 & 45 & -55 & 20 \\
\hline \multicolumn{7}{|c|}{ (B) Semantic Relatedness (Opaque Words) } \\
\hline L inferior temporal gyrus (BA 20) & 1875 & .0022 & 7.05 & -45 & 11 & -35 \\
\hline $\mathrm{R}$ inferior temporal gyrus (BA 20) & 1363 & .0022 & 6.46 & 54 & -19 & -28 \\
\hline $\mathrm{R}$ inferior temporal gyrus (BA 20) & & .0022 & 5.23 & 33 & 5 & -39 \\
\hline $\mathrm{R}$ anterior cingulate (BA 32) & 546 & .0022 & 5.75 & 9 & 35 & 29 \\
\hline R IFG orbitalis (BA 47) & 534 & .0022 & 5.43 & 48 & 17 & 6 \\
\hline \multicolumn{7}{|c|}{ (C) Semantic Relatedness (Opaque Productive Words) } \\
\hline LIFG (BA 45) & 1692 & .0039 & 5.40 & -42 & 38 & 14 \\
\hline LIFG (BA 47) & & .0062 & 5.27 & -39 & 47 & 2 \\
\hline $\mathrm{R}$ inferior temporal gyrus & 1294 & .0053 & 5.02 & 57 & -19 & -28 \\
\hline $\mathrm{R}$ fusiform & & .0039 & 5.01 & 42 & -22 & -24 \\
\hline $\mathrm{R}$ inferior temporal gyrus & & .0074 & 4.26 & 54 & -52 & -5 \\
\hline $\mathrm{R}$ insula & 217 & .0062 & 4.10 & 33 & 17 & -5 \\
\hline R IFG (BA 45) & & .0126 & 2.45 & 48 & 32 & 14 \\
\hline R IFG (BA 44) & & .04580 & 2.39 & 54 & 17 & 2 \\
\hline $\mathrm{L}$ anterior cingulate & 123 & .0067 & 3.80 & -9 & 44 & 2 \\
\hline R IFG (BA 44) & 45 & .0253 & 2.97 & 45 & 14 & 29 \\
\hline R IFG (BA 44) & & .0364 & 2.62 & 36 & 8 & 32 \\
\hline $\mathrm{R}$ precentral & & .0373 & 2.53 & 45 & 8 & 36 \\
\hline \multicolumn{7}{|c|}{ (D) Semantic Relatedness (Opaque Non-productive Words) } \\
\hline L fusiform & 617 & .0145 & 5.11 & -36 & -55 & -9 \\
\hline L fusiform & & .0161 & 4.54 & -30 & -49 & -16 \\
\hline L MTG (BA 22) & & .0145 & 4.49 & -41 & -58 & 14 \\
\hline
\end{tabular}


Table 6. (continued)

\begin{tabular}{|c|c|c|c|c|c|c|}
\hline \multirow[b]{2}{*}{ Regions } & \multirow[b]{2}{*}{ Cluster Extent } & \multirow[b]{2}{*}{ Voxel Level $p$} & \multirow[b]{2}{*}{ Pseudo-t } & \multicolumn{3}{|c|}{ Coordinates } \\
\hline & & & & $x$ & $y$ & $z$ \\
\hline $\mathrm{R}$ anterior cingulate & 211 & .0291 & 3.74 & 3 & 41 & 2 \\
\hline L IFG (BA 45) & 181 & .0161 & 3.82 & -42 & 20 & 6 \\
\hline L IFG (BA 47) & & .0294 & 2.92 & -36 & 35 & -16 \\
\hline R inferior temporal gyrus (BA 20) & 172 & .0145 & 4.88 & 48 & -55 & -9 \\
\hline R precentral (BA 6) & 110 & .0167 & 4.65 & 51 & 5 & 32 \\
\hline R IFG (BA 47) & 95 & .0145 & 3.31 & 27 & 32 & -16 \\
\hline R IFG (BA 45) & 35 & .0294 & 3.54 & 51 & 35 & -1 \\
\hline R IFG (BA 45) & & .0362 & 2.57 & 39 & 35 & 14 \\
\hline
\end{tabular}

Coordinates and voxel level peak significance values $(p)$ in each activation cluster.

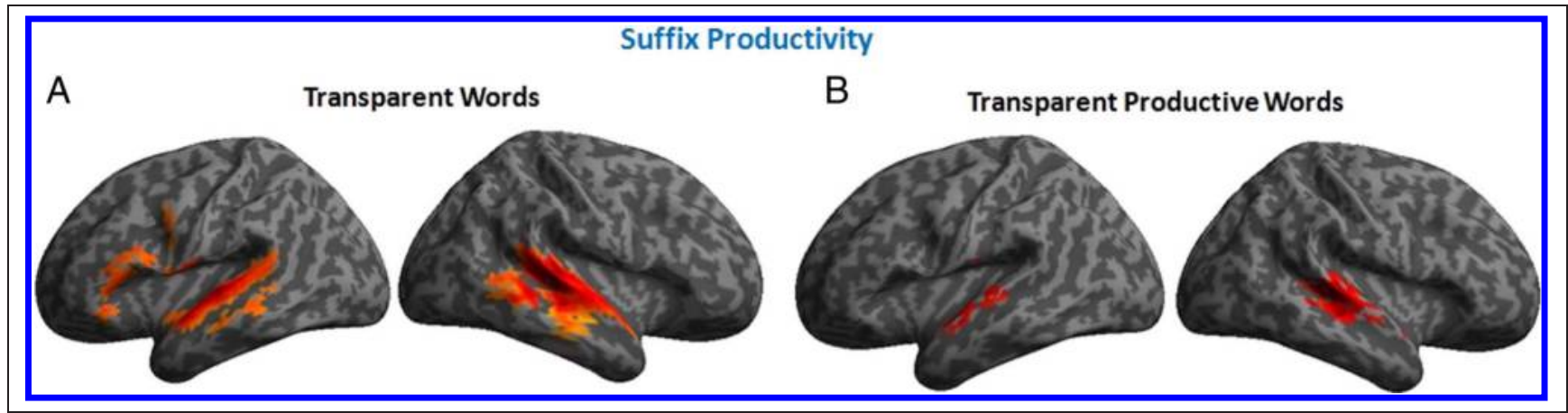

Figure 7. RSA Suffix Productivity analyses: Brain areas showing significant model fit for (A) Transparent words and (B) Transparent Productive words. All results are significant at FDR 0.05 .

Table 7. RSA Analyses for Suffix Productivity

\begin{tabular}{|c|c|c|c|c|c|c|}
\hline \multirow[b]{2}{*}{ Regions } & \multirow[b]{2}{*}{ Cluster Extent } & \multirow[b]{2}{*}{ Voxel Level p } & \multirow[b]{2}{*}{ Pseudo-t } & \multicolumn{3}{|c|}{ Coordinates } \\
\hline & & & & $x$ & $y$ & $z$ \\
\hline \multicolumn{7}{|c|}{ (A) Suffix Productivity (Transparent Words) } \\
\hline R MTG (BA 22) & 1031 & .0083 & 6.06 & 57 & -31 & 2 \\
\hline R STG (BA 21) & & .0108 & 4.55 & 60 & -7 & -1 \\
\hline R superior temporal pole (BA 38) & & .0083 & 4.30 & 57 & 11 & -5 \\
\hline L STG (BA 21) & 982 & .0083 & 6.28 & -60 & -19 & 6 \\
\hline L inferior frontal opercularis (BA 44) & & .0085 & 4.15 & -60 & 5 & 14 \\
\hline L inferior frontal opercularis (BA 44) & & .0213 & 3.37 & -45 & 11 & 29 \\
\hline \multicolumn{7}{|c|}{ (B) Suffix Productivity (Transparent Productive Words) } \\
\hline R MTG (BA 22) & 253 & .0380 & 4.88 & 48 & -34 & 2 \\
\hline R MTG (BA 22) & & .0384 & 4.84 & 57 & -28 & 2 \\
\hline L STG (BA 21) & 157 & .0427 & 4.03 & -60 & -22 & 6 \\
\hline L STG (BA 21) & & .0403 & 4.03 & -54 & -7 & -9 \\
\hline
\end{tabular}

Coordinates and voxel level peak significance values $(p)$ in each activation cluster. 
Szlachta, et al., 2013; Bozic, Tyler, et al., 2013; Bozic et al., 2010).

The conclusion that the processing activity elicited by the opaque items is primarily driven by the perceptual competition between two (or more) active lexical candidates is supported by the results for the semantic relatedness dimension. As noted earlier, relatedness varies not only in terms of the global contrast between opaque and transparent sets but also within each set separately. In the univariate analyses, the opaque conditions show increased levels of activation in bilateral temporal regions as semantic similarity decreases (Figure 3). The more semantically distinct the embedded stem and the full form, the stronger the perceptual competition between them. The multivariate analyses give a more differentiated but comparable picture. Again, no model fit is seen for the transparent word data. For the opaque sets, the relatedness RDM fits best in the Opaque Productive subset (Figure 6C), with substantial bilateral frontotemporal model fit. This encompassed ventral bilateral IFG (BA 47), a key area for semantic processing (Hagoort, 2005) and semantic retrieval (e.g., Wagner, Paré-Blagoev, Clark, \& Poldrack, 2001), as well as temporal pole and anterior MTG, regions essential for lexical retrieval and language comprehension (e.g., Turken \& Dronkers, 2011). Previous findings for English (Bozic, Szlachta, et al., 2013; Bozic, Tyler, et al., 2013) show a bilateral frontotemporal interaction between semantic relatedness and lexical competition, consistent with the findings here.

The univariate results for the productivity dimension are similarly consistent with a perceptual competition account, with decreased affix productivity leading to increased processing costs. Opaque nonproductive forms generate the highest levels of activation overall, relative to the opaque productive forms (Figure 2C), and the parametric modulator analysis (Figure 3) shows that this increased activation is associated with less productive affixes. The directionality of this effect and its location in bilateral inferior frontal areas involved in perceptual conflict resolution (Figure 3) suggest that opaque forms with nonproductive affixes generate stronger cohort competition than those with productive affixes. Nonproductive forms like ventura are more likely to be treated as nondecomposable simple lexemes in first-pass processing, fully distinct from their onset embedded pseudostems (e.g., vento), and therefore processed by the perceptual system in the same way as morphologically simple words with onset-embedded competitors such as ramp or claim.

These contrasts are likely to be less clearcut for opaque forms like tombino, "manhole," where the presence of a highly productive suffix like $\{$-ino $\}$ may lead to an initial missegmentation as $\{$ tomba $\}+\{$-ino $\}$, similar to the effects seen in the visual domain for English pseudocomplex words like corner, where the presence of the productive affix $\{$-er\} leads to a transient misanalysis of the morphologically simple corner as $\{$ corn $\}+\{$-er $\}$ (Whiting, Shtyrov, \& Marslen-Wilson, 2014; Rastle, Davis,
Marslen-Wilson, \& Tyler, 2000). In the current context, these processes would reduce competition effects relative to the opaque nonproductive condition, both by slowing the identification of the semantically unrelated opaque form actually present and by providing potential semantically related alternative readings (i.e., of tomba plus a suffix). Note that, on this account, the lexical representation of forms like tombino is assumed to be morphologically simple and unstructured, similar to lexically simple pseudocomplex forms like corner or brother in English.

\section{Transparent Forms}

Focusing first on the transparent forms with productive affixes, these contrast strongly with the opaque forms, showing no sign of competition or relatedness effects in either univariate or multivariate analyses, while revealing significant left-lateralized effects of suffix productivity in the multivariate RSA analyses.

These robust differences between transparent productive words and opaque words point to a view of the representation and processing of transparent productive forms that is strikingly similar to the proposals put forward by Marslen-Wilson et al. (1994) on the basis of purely behavioral priming studies of derivationally complex forms in English. These proposals had two components that are relevant here. The first was that the central representation of derivationally complex forms was determined by their semantic transparency, with only transparent forms (such as happiness) being decompositionally represented (as $\{$ happy $\}+\{$-ness $\}$ ), whereas opaque forms were represented as whole forms (e.g., $\{$ department $\}$ ) with no link to their semantically and morphologically unrelated onset-embedded lexemes (e.g., $\{$ depart $\}$ ). The second component, required to explain the robust priming between happiness and happy (but not between department and depart), was that the same abstract morpheme functioned both as an independent lexeme and as a combinatorial component of the family of derived forms transparently related to this morpheme (e.g., happiness, happily, unhappy, etc.).

Functionally equivalent proposals seem required herein particular, to explain why libro, "book," does not function as a cohort competitor to libreria, "bookshop." There is little doubt that a form like libro is a separate lexeme in the language, which predicts that libreria should generate cohort competition in the same way as an opaque form like ventura "manhole," where the synchronically unrelated stem vento "tomb" is activated as a cohort competitor. We see instead that representational overlap (because of semantic transparency) between a derived form and its embedded stem, while driving priming in the behavioral study, seems to neutralize cohort competition in the neural domain.

This decompositional view of the representation and processing of the transparent productive forms may well 
be linked to the second major divergence between these forms and the opaque sets. This is in the domain of affix productivity, where the RSA analyses reveal significant model fit only for the transparent conditions. These effects implicate the left perisylvian language system, with the characteristic pattern of bilateral temporal involvement accompanied by selective LIFG model fit, primarily in left BA 44. These are brain regions-especially the BA 44/45 and left posterior STG network identified in earlier studies (e.g., Bozic et al., 2015; Marslen-Wilson \& Tyler, 2007; Tyler, Stamatakis, Post, Randall, \& Marslen-Wilson, 2005)with a well-established role in supporting decompositional and combinatorial processing for inflected forms and for syntactically complex phrases and sentences. This suggests that the processing and representation of transparent derivational forms, at least in a root-based word formation system like Italian (Crepaldi, Morone, Arduino, \& Luzzatti, 2014), does share some processing characteristics with inflectionally complex forms, with the derivational affix being separately identified as part of the perceptual access process. Note, however, that this does not imply that Italian derivational affixes participate in phrasal and sentential level morphosyntactic processes in the same way as inflectional affixes. Exactly how they do interface with left perisylvian combinatorial machinery is an issue for further research.

We turn, finally, to the transparent forms with unproductive affixes, such as pineta, "pine forest" or fornaio, "baker" (combining forno "oven" with the unproductive agentive suffix $\{$-aio $\}$ ). These elicit a third class of effects, intermediate between the results for the productive transparent and the opaque sets, which are consistent with earlier results for English forms such as warmth, which indicated that transparent forms with unproductive suffixes are less readily decomposable, despite their semantic relatedness (Bozic, Tyler, et al., 2013; Ford et al., 2010; Marslen-Wilson et al., 1996). In the current research, the greater lexemic independence of the derived form seems to lead to significant but paradoxical effects of relatedness and competition.

For opaque nonproductive forms, such as ventura, it is the dissimilarity between two competing lexemes (vento and ventura), reflected in decreased semantic relatedness and increased competition ratio, that leads to stronger cohort competition and increased neural activation. For transparent nonproductive forms like pineta, in contrast, it is the similarity between potentially competing lexemes (pino and pineta) that seems to increase activation. As the full form and the onset-embedded stem become more similar, whether in their semantic properties or in their relative frequencies of occurrence, then neural activation increases. This presumably reflects greater difficulty in discriminating the two lexemes involved (cf., Raposo, Moss, Stamatakis, \& Tyler, 2006).

These surprising contrasts suggest two things. First, that the strong representational overlap between forms like pineta and pino, in terms of their rated semantic properties, acts to mitigate cohort competition based on dissimi- larity, just as it does for the transparent productive forms. At the same time, however, the apparently greater lexemic differentiation between stem and derived form opens the door for a different type of selection problem, reflecting the degree of similarity between the two forms. The implications of these contrasts, however, for the representational differences between productive and unproductive forms, remain a question for further research.

\section{Conclusions}

The results reviewed here for the transparent forms in this experiment-most clearly for those with productive affixes-lead to the conclusion that the same underlying representation, in whatever way it is neurocomputationally realized, participates in the activation of the transparent derived forms and in the activation of their stems. The neuroimaging results are the most direct evidence for this because they do not reflect potential behavioral task demands_-as associated, for example, with lexical decision (Wright et al., 2010) — but simply the patterns of neural activation elicited as the listener hears a spoken word. These patterns point to an underlying decompositional and combinatorial substrate for the neural representation of semantically transparent derivationally complex forms. The dynamic neural substrate for a form like libreria incorporates the neural substrate for its stem libro, reducing cohort competition - and explaining behavioral priming.

This decompositional interpretation is supported by the presence of selective left perisylvian neural activity (Figure 7A), diagnostic of linguistically relevant combinatorial processing, that is tied to the affix productivity of these transparent forms. More generally, this account is consistent with earlier psycholinguistic proposals (e.g., Marslen-Wilson, 2007; Clahsen et al., 2003; Marslen-Wilson et al., 1994), as well as with realization-based linguistic accounts (e.g., Anderson, 1992), which posit that derivational rules map the entry of the stem onto the derived form.

These conclusions, if correct, suggest significant crosslinguistic variation in the extent to which derivationally complex forms are represented and accessed by domaingeneral bihemispheric systems and in their degree of engagement with the more domain-specific left perisylvian system. For Italian, it is only the opaque nonproductive forms that fully fit the picture of the derived word as a nondecomposed whole form that interacts primarily with the bilateral frontotemporal system and whose dominant processing signature is the cohort competition that it generates. The opaque forms with productive affixes, while also generating bilateral cohort competition effects, trigger a greater degree of decompositional activity, being affected by semantic relatedness and affix productivity. This activity, however, may represent bottom-up processes of missegmentation, driven by the presence of the productive affix, rather than reflecting the representation of the target item itself. The fully transparent productive forms, with a decompositional representational structure and strongly 
reduced cohort competition effects, also activate bilateral temporal regions but in addition engage left perisylvian processes likely to be related to their decompositional structure. Whether this simply reflects the greater combinatorial complexity of Italian derived forms, relative to English, cannot be determined at present.

A final major dimension of cross-linguistic variation involves the centrality of semantic transparency in determining whether or not a derived form representationally incorporates its stem. For Italian, as for English and Polish, the semantic dimension seems the principal determinant. For a Semitic language such as Arabic, with its nonconcatenative word formation processes, behavioral priming between two forms does not depend on semantic transparency. It is driven instead by the presence of a shared morpheme (the root or the word pattern) between prime and target (Boudelaa \& Marslen-Wilson, 2015), indicating that representational overlap between different lexemes can be based on the morphosyntactic rather than the semantic properties of the relationship between them. A more general account of how morphological complexity is neurally represented across the world's languages will have to take on board this apparently fundamental difference in the basic principles in terms of which these representations are organized in different language families.

\section{Acknowledgments}

This research was supported by an Advanced Investigator grant to W. M. W. from the European Research Council (AdG 230570 NEUROLEX) and by MRC Cognition and Brain Sciences Unit (CBSU) funding to W. M. W. (U.1055.04.002.00001.01). Computing resources were provided by the MRC CBSU. We thank Timothy Ives for his assistance with the Musical Rain baseline stimuli and Samarth Varma for his assistance with the pilot acquisitions.

Reprint requests should be sent to Francesca Carota, Department of Psychology, University of Cambridge, Downing Street, Cambridge, CB2 3EB, United Kingdom, or via e-mail: fc360@ cam.ac.uk, francesca.carota@cantab.net.

\section{Note}

1. Such resources were not readily available for the Bozic, Szlachta, et al. (2013) study in Polish; hence, the absence of an affix productivity contrast in that experiment.

\section{REFERENCES}

Anderson, S. R. (1992). A-morphous morphology. Cambridge: Cambridge University Press.

Baayen, H., \& Lieber, R. (1991). Productivity and English derivation: A corpus-based study. Linquistics, 29, 801-844.

Badecker, W., \& Caramazza, A. (1991). Morphological composition in the lexical output system. Cognitive Neuropbysiology, 8, 335-357.

Baroni, M., Bernardini, S., Ferraresi, A., \& Zanchetta, E. (2009). The WaCky wide web. A collection of very large linguistically processed web-crawled corpora. Language Resources and Evaluation, 43, 209-231.

Binder, J. R., Frost, J. A., Hammeke, T. A., Cox, R. W., Rao, S. M., \& Prieto, T. (1997). Human brain language areas identified by functional magnetic resonance imaging. Journal of Neuroscience, 17, 353-362.

Bokde, A. L., Tagamets, M. A., Friedman, R. B., \& Horwitz, B. (2001). Functional interactions of the inferior frontal cortex during the processing of words and word-like stimuli. Neuron, 30, 609-617.

Botvinick, M., Cohen, J. D., \& Carter, C. S. (2004). Conflict monitoring and anterior cingulate cortex: An update. Trends in Cognitive Sciences, 8, 539-546.

Boudelaa, S., \& Marslen-Wilson, W. D. (2015). Structure, form and meaning in the mental lexicon: Evidence from Arabic. Language. Cognition. \& Neuroscience, 30, 955-992.

Bozic, M., Fonteneau, E., Su, L., \& Marslen-Wilson, W. D. (2015). Grammatical analysis as a distributed neurobiological function. Human Brain Mapping, 36, 1190-1201.

Bozic, M., Szlachta, Z., \& Marslen-Wilson, W. D. (2013). Cross-linguistic parallels in processing derivational morphology. Brain and Lanquage, 127, 533-538.

Bozic, M., Tyler, L. K., Ives, D. T., Randall, B., \& Marslen-Wilson, W. D. (2010). Bihemispheric foundations for human speech comprehension. Proceedings of the National Academv of Sciences, U.S.A., 107, 17439-17444.

Bozic, M., Tyler, L. K., Wingfield, C., Su, L., \& Marslen-Wilson, W. D. (2013). Neurobiological systems for lexical representation and analysis in English. Journal of Cognitive Neuroscience, 25, 1678-1691.

Butterworth, B. (1983). Lexical representation. In B. Butterworth (Ed.), Language production (Vol. 2, pp. 257-294). London: Academic Press.

Carota, F. (2006). Italian derivational morphology: Principles for formalization. Literary and Linguistic Computing, 21, 25-53.

Clahsen, H., Sonnenstuhl, I., \& Blevins, J. P. (2003). Derivational morphology in the German mental lexicon: A dual mechanism account. In H. Baayen \& R. Schreuder (Eds.), Morphological structure in language processing (pp. 125-155). Berlin: Mouton de Gruyter.

Crepaldi, D., Morone, E. A., Arduino, L. S., \& Luzzatti, C. (2014). Morphological processing of printed nouns and verbs: Cross-class priming effects. Journal of Cognitive Psychology, 26, 433-460.

Ford, M. A., Davis, M. H., \& Marslen-Wilson, W. D. (2010). Deriviational morphology and base morphene frequency. Journal of Memorv and Language, 63, 117-130.

Grossman, M., \& Rainer, F. (2004). La formazione delle parole in italiano. Tübingen: Niemeyer.

Hagoort, P. (2005). On Broca, brain, and binding: A new framework. Trends in Cognitive Sciences, 9, 416-423.

Iacobini, C. (2010). Nomi denominali. In R. Simone (Ed.), Enciclopedia dell'italiano (pp. 347-349). Roma: Istituto dell'Enciclopedia Italiana.

Klimovich-Smith, Bozic, \& Marslen-Wilson (Under review). Perceptual complexity and grammatical processing in left perisylvian cortex: Evidence from Russian.

Kriegeskorte, N., Mur, M., \& Bandettini, P. (2008). Representational similarity analysis - Connecting the branches of systems neuroscience. Frontiers in Systems Neuroscience, 2, 1-28.

Leminen, A., Leminen, M., Lehtonen, M., Nevalainen, P., Ylinen, S., Kimppa, L., et al. (2011). Spatiotemporal dynamics of the processing of spoken inflected and derived words: A combined EEG and MEG study. Frontiers in Human Neuroscience, 5, 1-14.

Marangolo, P., Incoccia, C., Pizzamiglio, L., Sabatini, U., Castriota-Scanderbeg, A., \& Burani, C. (2003). The right hemisphere involvement in the processing of morphologically derived words. Journal of Cognitive Neuroscience, 15, 364-371.

Marslen-Wilson, W. D. (1987). Functional parallelism in spoken word-recognition. Cognition, 25, 71-102. 
Marslen-Wilson, W. D. (2007). Morphological processes in language comprehension. In G. Gaskell (Ed.), Oxford Handbook of Psycholinguistics (pp. 175-193). Oxford: Oxford University Press.

Marslen-Wilson, W. D., Bozic, M., \& Tyler, L. K. (2014). Morphological systems in their neurobiological contexts. In M. S. Gazzaniga \& G. R. Mangun (Eds.), The cognitive neurosciences (5th ed., pp. 639-648). Cambridge, MA: MIT Press.

Marslen-Wilson, W. D., \& Tyler, L. K. (2007). Morphology, language and the brain: The decompositional substrate for language comprehension. Philosophical Transactions of the Royal Society, Biological Sciences, 362, 823-836.

Marslen-Wilson, W. D., Tyler, L. K., Waksler, R., \& Older, L. (1994). Morphology and meaning in the English mental lexicon. Psvchological Review, 101, 3-33.

Meinzer, M., Lahiri, A., Flaisch, T., Hannemann, R., \& Eulitz, C. (2009). Opaque for the reader but transparent for the brain: Neural signatures of morphological complexity. Neuropsychologia, 47, 1964-1971.

Meunier, F., \& Segui, J. (2002). Cross-modal morphological priming in French. Brain and Lanquage, 83, 89-102.

Nili, H., Wingfield, C., Walther, A., Su, L., Marslen-Wilson, W., \& Kriegeskorte, N. (2014). A toolbox for representational similarity analysis. PLoS Computational Biologv, 10, e1003553.

Plag, I. (2006). Productivity. In B. Aarts \& A. McMahon (Eds.), The handbook of English linguistics (pp. 537-556). Oxford: Blackwell.

Raposo, A., Moss, H. E., Stamatakis, E. A., \& Tyler, L. K. (2006). Repetition suppression and semantic enhancement: An investigation of the neural correlates of priming. Neuropsychologia, 44, 2284-2295.

Rastle, K., Davis, M., Marslen-Wilson, W. D., \& Tyler, L. K. (2000). Morphological and semantic effects in visual word recognition: A time course study. Language and Cognitive Processes, 15, 507-538.

Reid, A. A., \& Marslen-Wilson, W. D. (2003). Lexical representation of morphologically complex words: Evidence from Polish. In Baayen, R. H. \& Schreuder, R. (Eds.), Morphological Structure in Language Processing (pp. 287-336). Berlin and New York: Mouton de Gruyter.

Szlachta, Z., Bozic, M., Jelowicka, A., \& Marslen-Wilson, W. D. (2012). Neurocognitive dimensions of lexical complexity in Polish. Brain and Language, 121, 219-225.

Taft, M. (2004). Morphological decomposition and the reverse base frequency effect. Ouarterlv Iournal of Experimental Psychology, 57A, 745-765.

Thompson-Schill, S. L., D'Esposito, M., \& Kan, I. P. (1999). Effects of repetition and competition on activity in left prefrontal cortex during word generation. Neuron, 23, 513-522.

Turken, A. U., \& Dronkers, N. F. (2011). The neural architecture of the language comprehension network: Converging evidence from lesion and connectivity analyses. Frontiers in Sustems Neuroscience, 5, 1.

Tyler, L. K., \& Marslen-Wilson, W. D. (2008). Fronto-temporal brain systems supporting spoken language comprehension. Philosophical Transactions of the Roval Societv of London B: Biological Sciences, 363, 1037-1054.

Tyler, L. K., Stamatakis, E. A., Post, B., Randall, B., \& Marslen-Wilson, W. D. (2005). Temporal and frontal systems in speech comprehension: An fMRI study of past tense processing. Neuropsychologia, 43, 1963-1974.

Uppenkamp, S., Johnsrude, I. S., Norris, D., Marslen-Wilson, W. D., \& Patterson, R. D. (2006). Locating the initial stages of speech-sound processing in human temporal cortex. Neuroimage, 31, 1284-1296.

Wagner, A. D., Paré-Blagoev, E. J., Clark, J., \& Poldrack, R. A. (2001). Recovering meaning: Left prefrontal cortex guides controlled semantic retrieval. Neuron, 31, 329-338.

Whiting, C., Shtyrov, Y., \& Marslen-Wilson, W. D. (2014). Real-time functional architecture of visual word recognition. Iournal of Cognitive Neuroscience, 27, 246-265.

Wright, P., Randall, B., Marslen-Wilson, W. D., \& Tyler, L. K. (2011). Dissociating linguistic and task-related activity in LIFG. Journal of Cognitive Neuroscience, 23, 404-413.

Zhuang, J., Tyler, L. K., Randall, B., Stamatakis, E. A., \& Marslen-Wilson, W. D. (2014). Optimally efficient neural systems for processing spoken language. Cerebral Cortex. 24, 908-918. 
This article has been cited by:

1. Mohammad Momenian, Reza Nilipour, Reza Ghafar Samar, Stefano F. Cappa, Narly Golestani. 2018. Morpho-syntactic complexity modulates brain activation in Persian-English bilinguals: An fMRI study. Brain and Language 185, 9-18. [Crossref]

2. Alina Leminen, Eva Smolka, Jon A. Duñabeitia, Christos Pliatsikas. 2018. Morphological processing in the brain: The good (inflection), the bad (derivation) and the ugly (compounding). Cortex . [Crossref]

3. Pienie Zwitserlood. Processing and Representation of Morphological Complexity in Native Language Comprehension and Production 583-602. [Crossref]

4. Yun-Hsuan Yang, William D. Marslen-Wilson, Mirjana Bozic. 2017. Syntactic Complexity and Frequency in the Neurocognitive Language System. Journal of Cognitive Neuroscience 29:9, 1605-1620. [Abstract] [Full Text] [PDF] [PDF Plus] 